\title{
Should we use Commitment Contracts to Regulate Student use of Cognitive Enhancing Drugs?
}

\author{
By John Danaher
}

Forthcoming in Bioethics

\begin{abstract}
Are universities justified in trying to regulate student use of cognitive enhancing drugs? In this paper I argue that they can be, but that the most appropriate kind of regulatory intervention is likely to be voluntary in nature. To be precise, I argue that universities could justifiably adopt a commitment contract system of regulation wherein students are encouraged to voluntarily commit to not using cognitive enhancing drugs (or to using them in a specific way). If they are found to breach that commitment, they should be penalised by, for example, forfeiting a number of marks on their assessments. To defend this model of regulation, I adopt a recently-proposed evaluative framework for determining the appropriateness of enhancement in specific domains of activity, and I focus on particular existing types of cognitive enhancement drugs, not hypothetical or potential forms. In this way, my argument is tailored to the specific features of university education, and common patterns of usage among students. It is not concerned with the general ethical propriety of using cognitive enhancing drugs.
\end{abstract}

Keywords: Enhancement; Education; Ethics; Practice-Oriented Activities; Modafinil; Methylphenidate; Commitment Contracts 


\section{Introduction}

Concerns about student use of cognitive enhancing drugs have been around for some time. ${ }^{1}$ Some universities have already taken to banning such usage. ${ }^{2}$ Are such regulatory actions appropriate? In this article, I argue that the use of enhancing drugs by students may warrant some modest forms of regulation on the part of the university. To be precise, I argue that universities could justifiably regulate student use of cognitive enhancing drugs through a system of voluntary commitment contracts because such a regulatory system would help to mitigate the primary education-undermining vice of such drug usage. I defend this argument in two parts. First, I adopt a recently-proposed evaluative framework for determining the normative attitude one should take toward enhancement technologies in specific domains of activity. This framework allows us to argue that the typical usage pattern for cognitive enhancing drugs in higher education may subvert one of the core values of higher education and hence some regulatory intervention may be justified. Second, I focus on the particular mechanisms of subversion highlighted in the first argument to make the case for a particular model of regulatory intervention based on the use of voluntary commitment contracts.

In developing these two arguments, I focus on the most-commonly discussed and popular forms of cognitive enhancing drug (e.g. dextroamphetamines, methylphenidates and modafinil), ${ }^{3}$ not on hypothetical or potential forms; and in particular on the use of these drugs by students at university. In this respect, my argument is tailored to specific aspects of the use of enhancement drugs by university students and the specific educational mission of the university; it is not primarily focused on general ethical concerns about the use of enhancement drugs, except to the extent that they have relevance in that specific context.

\footnotetext{
${ }^{1}$ Greely, H.T. et al. Toward responsible use of cognitive enhancing drugs by the healthy. Nature 2010, 456: 702-705

${ }^{2}$ For example, Duke University: http://studentaffairs.duke.edu/conduct/z-policies/academic-dishonesty

${ }^{3}$ This is not an exhaustive list of potentially enhancing drugs, but does represent those most commonly analysed in the ethical debate and empirical literature. It also deliberately excludes certain forms of enhancement such as tDCS. There is no strong justification for this, except that there is more evidence about pharmacological enhancers, and, in any event, the basic evaluation I undertake could be applied to other forms of enhancement as well. Different conclusions may be reached in those cases, but that it simply because the evaluative method adopted in this article is deliberately designed so as to be tailored to the specific facts concerning any putative enhancement technology.
} 


\section{The Evaluative Framework}

The evaluative framework comes from the work of Santoni de Sio and colleagues. ${ }^{4}$ The framework proposes that the normative attitude one should take toward enhancement depends on the nature of the activity in which one is interested. I adopt it here because it highlights the key features of education. In doing so, I sidestep some of the more traditional ethical argumentative categories used in the enhancement debate (like harm, fairness, cheating, authenticity and so on). This is deliberate. For one thing, it is not clear that those categories are all that useful in the context of the enhancement debate. Though we should certainly care about these broader ethical issues, several authors have argued that harm, fairness and authenticity arguments are largely neutral with respect to the permissibility of enhancement in particular activities (at least, they are neutral without considerable further elaboration). ${ }^{5}$ In addition to this, as I just mentioned, the argument I present is concerned specifically with the university and the normative aspects of its educational mission. Broader ethical issues aren't irrelevant to this mission, of course, but there are specific normative features of the educational mission that are important when it comes to assessing the permissibility of enhancement. At least, that is what Santoni de Sio and colleagues' framework helps to establish.

The evaluative framework begins by suggesting that human activities can be divided into two general types: practice-oriented activities, which are concerned with a particular kind of performance or performative act (and the internal goods associated with that performance); and goal-directed activities, which are concerned with a particular kind of outcome (and the external goods associated with that outcome). ${ }^{6}$ An example of the former might be a sporting activity like the $100 \mathrm{~m}$ sprint, which although it has an end-goal, cares primarily about a particular kind of performative act. For example, you must run to the finish line, not crawl or rollerblade. An example of a goaldirected activity — one mentioned by Santoni di Sio and his colleagues ${ }^{7}$ — might be scientific research. The goal of research is to produce new results, theories and insights. It does not matter how those results are achieved (though, of course, some

\footnotetext{
${ }^{4}$ Santoni de Sio, F., Robichaud, P. and Vincent, N. Who should enhance? Conceptual and normative dimensions of cognitive enhancement. Humana Mente 2014, 26: 179-197

${ }^{5}$ Schermer, M. On the Argument That Enhancement Is 'cheating'. Journal of Medical Ethics 2008, 34(2): 85 - 88; Savulescu, J., Foddy, B. \& Clayton, M. Why We Should Allow Performance Enhancing Drugs in Sport. British Journal of Sports Medicine 2004, 38(6): 666-670

${ }^{6}$ Agar, N. Truly Human Enhancement. Cambridge, MA: MIT Press 2014 - discusses the notion of internal and external goods at some length.

${ }^{7}$ Santoni de Sio et al (n 2), p 186.
} 
methodologies will be more inclined to be successful than others). These two categories are abstract and general. Most human activities will fail to bifurcate neatly into one or the other and will share elements of both. We see this even in the example of the $100 \mathrm{~m}$ sprint, which although it is primarily about performance is also, at least partly, about outcomes. This blending of the two categories will also be true for education, as we shall see below, because although there are clearly end-goals to the educational process (developing virtues; securing employment etc), there are also clearly performative skills that one must develop in order to properly attain those end-goals.

The distinction between the practice and outcome-oriented aspects of an activity is important when it comes to evaluating the use of enhancement technologies. In the case of a purely outcome-directed activity, the only normative concerns one would have about the use of enhancement would arise from the standard ethical questions: Is the enhancement harmful? Is its use fair, safe, authentic and so forth? These ethical questions are important and should not be ignored, but as I mentioned above, many of them are neutral or unhelpful with respect to the permissibility of enhancement in particular domains. For instance, fairness arguments often cut both ways. If you wish to ensure a level playing field between the participants in a particular activity, you can achieve this by leveling up (i.e. allowing the use of enhancement) or leveling down (forbidding it). Similarly, harm arguments are often unhelpful in the enhancement debate because (a) many activities are intrinsically harmful (this includes many sporting activities in which the use of performance enhancers is routinely banned, e.g. combat sports) and (b) it is often unclear whether the enhancement drugs are any more harmful than other permissible methods of performance enhancement (e.g. strenuous training methods are often harmful to athletes seeking to improve their performance, but we don't ban them whereas we do ban performance enhancing drugs which may often be less harmful, if managed appropriately). Finally, authenticity-based arguments are typically unhelpful because the very concept of an authentic performance or act is fuzzy and contested. If an authentic performance is simply one that is expressive of one's true self, then it is not clear why the use of an enhancer blocks true self-expression. ${ }^{8}$ On the

\footnotetext{
${ }^{8}$ For example, assume that a true act of self-expression is one that is consistent with your higher order preferences and desires. Nevertheless, you have lower order preferences and desires that are in tension with or undermine those higher order preferences (such as the preference for procrastination or impulsivity). In such a scenario, the use of an enhancer may facilitate true self-expression by blocking those lower order preferences. This is hypothetical, of course, but illustrates the problem with using authenticity as a ground for justifying a regulatory intervention. For further discussion see: Erler A. Authenticity. In: Jennings B (ed) Bioethics, 4th edn. MacMillan Reference USA, Farmington Hills 2014; and Danaher, J. Human Enhancement, Social Solidarity and the Distribution of Responsibility. Ethical Theory and Moral Practice 2015 DOI 10.1007/s10677-015-9624-2
} 
other hand, if an authentic performance is simply one that is true to the internal goods of the activity in question, then we return to the question of what those internal goods might be. This is exactly what Santoni de Sio and colleagues' evaluative framework focuses on. So, in other words, authenticity arguments of this second type collapse into the type of argument I wish to defend in this article.

In the case of purely practice-oriented activities, these ethical concerns still play a part, but they are complemented by an important set of internal normative concerns as well. In particular, they are complemented by a concern that certain changes in the methods of performance can subvert the point of the activity (i.e. result in some other type of activity being performed and thereby undermine the internal goods of the activity). For example, somebody who rollerbladed up the sprint track would be subverting the point of the $100 \mathrm{~m}$ sprint. The internal good of that activity comes from a particular type of performance, namely: running down the track. Using a piece of technology, in this case the rollerblade, to reach the end-goal in a different fashion compromises those internal goods. Consequently, there are good reasons for thinking that rollerblades should be banned when it comes to the performative aspects of this activity. This doesn't mean that rollerblades should be banned in other activities - that would depend on a variety of other factors, such as harmfulness. By focusing on the practice-oriented virtues of the activity, the argument for the ban becomes domainspecific. What Santoni de Sio and colleagues suggest, and what I want to argue here, is that what is true for rollerblades in the $100 \mathrm{~m}$ sprint, could also be true of the use of enhancement drugs in specific domains, particularly education. In other words, I want to suggest that there may be good reason for regulatory intervention into the use of enhancement drugs by students, irrespective of their harmfulness or impact on fairness or otherwise. This would be because their use may subvert the point of education and undermine its internal goods. ${ }^{9}$

What I have just said pertains to purely practice-oriented activities, i.e. activities whose entire character is determined by compliance with a certain set of performative norms, and in which outcomes are not a significant concern. But as I noted previously, most activities are not purely practice-oriented or purely outcome-oriented. Instead, they blend elements of both. Fortunately, this does not greatly affect the application of

\footnotetext{
${ }^{9}$ I should note that Santoni di Sio et al (n 2), p. 186-87 claim that education is practice-oriented and that enhancement may subvert it. However, I ignore that claim here since it is merely offered to illustrate how their framework might apply. It is not completely justified.
} 
the proposed evaluative framework. As long as the activity in question consists of some performative norms (i.e. some internal goods that are tied to a particular method of performance) then it is possible to apply the domain-specific argument. This may be true even if, at first glance, the activity in question seems to be primarily outcomeoriented because it could be that the outcome-oriented goods are only made possible through a particular kind of performance.

This gives us everything we need to develop the evaluative framework for my argument. Since I will be proposing a semi-restrictive model of regulation (one that seeks to either ban or modulate usage), I focus here on the form that this evaluative framework takes when we wish to determine whether the use of enhancement should be limited within a particular domain of activity. For this to happen, three conditions must be met:

(A) The activity must be partly practice-oriented (i.e. must consist of some set of internal goods that are associated with a particular method of performance).

(B) The internal goods of the activity must be socially or morally valuable.

(C) The use of cognitive enhancement drugs must subvert those goods.

The first and third conditions are relatively straightforward, following on directly from what I just said. The second requires some explanation. It is introduced because some practice-oriented activities have very little intrinsic or instrumental value attached to their specific methods of performance. Santoni de Sio and his colleagues give examples like recreational sudoko-solving. In cases like this, where there is little of social or moral value at stake, it would seem inappropriate to intervene in and control the use of enhancement drugs by the participants. The individual should be left to determine the limits of the activity for themselves. But in cases where there is something of social or moral value attached to a particular kind of performance, things are different. In those cases, there is reason to worry that the use of enhancement may subvert what is socially or morally valuable about the activity and hence there is ground upon which to justify regulatory intervention. For present purposes, I assume that social value is determined by what is in the public interest, i.e. whatever is a public good that is worth preserving. This could include things like the civic-mindedness and intellectual 
capabilities of the citizenry in a democratic state. I also assume that moral value can be construed broadly to include things that benefit the moral character of the individual performing the activity. Consequently, I am going to argue that education is (in significant part) a practice-oriented activity where there are internal goods associated with a particular kind of performance which has some social and moral value. This seems like a plausible claim. Education certainly looks like it develops performative skills that benefit the public at large (a more engaged, critical and reflective citizenry) and also develops the moral character of the student, including the performative intellectual virtues that are essential to a fully rounded moral character. What is less clear is whether the use of enhancement drugs undermines those performative skills and if so what the appropriate regulatory intervention might be. I will try answer both of these questions over the remainder of the article. I do so with two distinct, but related arguments.

It is worth offering a general statement of both arguments now. The first argument works something like this (note: this is not intended to be formally valid - there is a gap between (4) and (5) that I will discuss in the final section):

(1) Higher education is at least partly practice-oriented and one of (if not the) most important performative skills it aims to develop is the skill of critical thinking.

(2) The performative skill of critical thinking depends crucially on deliberate practice and spaced repetition.

(3) Extant cognitive enhancing drugs (such as methylphenidate, dextroamphetamines and modafinil), particularly in light of their dubious enhancing effects and typical usage patterns, undermine deliberate practice and spaced repetition.

(4) Therefore, extant cognitive enhancing drugs (such as methylphenidates, dextroamphetamines and modafinil) undermine the practice-oriented virtues of most forms of higher education.

(5) Therefore, the university is justified in pursuing some regulatory intervention into the use of cognitive enhancing drugs. 
The second argument builds onto the end of this first argument. It does so by examining the exact mechanisms through which enhancing drugs undermine critical thinking and proposing a regulatory intervention that is consistent with the ethos of the university. This is what leads to my suggestion that a voluntary commitment contract system of regulation is an appropriate regulatory intervention.

\section{What are the performative goods of university education?}

The first thing that needs to be addressed is whether education is, in fact, partly practice-oriented and if so what kinds of practice-oriented virtues does it aim to cultivate among students. For many, it may simply be obvious that education is partly practice-oriented, but some may have their doubts. There are several reasons for this and it is worth considering them in some detail.

One problem for the practice-oriented view is that in most modern university courses, professors are encouraged to develop a set of "intended learning outcomes" (ILOs). ILOs can include things like knowledge acquisition, skills development, and so on. Professors then use various methods of assessment to determine whether the students have achieved the ILOs. This may create the impression that university education is a goal-directed activity: one that is designed to get students to achieve particular kinds of outcome. And indeed, there are many pressures bearing on modern education that encourage one to take an instrumentalist view of the process. Universities are sometimes perceived and advertised as being little more than factories churning out people to perform economically or socially valuable functions.

There is surely something to this - no one would deny the outcome-oriented aspects of education - but a moment's reflection shows that this strictly instrumentalist view must be wrong. For example, in developing my applied ethics module, one of my ILOs might be to get my students to write a sound logical argument for an ethical conclusion. This requires them to produce an output (an essay presenting the argument), and I measure their educational attainment on the basis of that output, but I clearly don't just want them to produce the output. I want them to produce that output through a certain kind of performance, one involving serious reflection on the issues, careful analysis, and evaluation. The output is only relevant because it provides proxy evidence 
of that performance. This is why universities are so concerned about things like plagiarism or online essay mills. If one can pay another to do the work (or steal from another) one subverts the point of educational activity by bypassing the required performance.

This suggests that education can be viewed as at least partly a practice-oriented activity. But this conclusion may be too hasty. The example I chose comes from a particular subject (applied ethics). It may be that what predominates varies from subject to subject. For example, one might argue that professional forms of education - e.g. the education of future doctors or lawyers — are essentially goal-directed. ${ }^{10}$ Why? Because the professions in question are essentially goal-directed. Being a good doctor or a good lawyer is determined by one's ability to produce a certain outcome (a cure for one's patient, or a win for one's client). So maybe education in these areas should simply encourage students to do whatever it takes to produce the right outcome? This could easily encompass encouraging or obliging them to use enhancement drugs.

Developing a 'win at all costs'-attitude might be exactly what we want.

Of course, this can't be quite right. Both professions encourage their practitioners to abide by other ethical standards (e.g. harm avoidance; fairness and so forth). Thus, a doctor cannot pursue a cure for a patient 'at all costs', particularly if those costs involve harming other putative patients. But this is simply to say that the performance of those professional activities is governed by external ethical considerations. What we are concerned with here is whether the professional performance is subject to other internal normative considerations and, at least at first glance, this does not appear to be the case. The upshot of all this is that we might be led to the conclusion that nothing predominates in education: some forms of education are primarily practice-oriented, others are not. Consequently, one could never reach a conclusion about what is, or is not, permissible with respect to enhancement in education in general. It will vary at a subject and module-specific level.

\footnotetext{
${ }^{10}$ In German, such education might be referred to as "Ausbildung" or "Erziehung" because it is about the acquisition of relevant professional abilities. It is to be contrasted with Bildung, which involves self-transformation and selfcultivation. This concept comes from von Humboldt: Sorkin, D.. Wilhelm Von Humboldt: The Theory and Practice of Self-Formation (Bildung), 1791-1810. Journal of the History of Ideas. 1983, 44 (1), 55-73. It has parallels in the English-speaking world with the distinction between liberal and vocational education. See, for example, the work of Alasdair McIntyre on education: McIntyre, A. Alasdair McIntyre on Education: In Conversation with Joseph Dunne. Journal of Philosophy of Education. 2002, 36(2): 2-19
} 
But I think this may also be wrong. If we reflect a little further on the professional example, we find that even if ${ }^{11}$ the professions in question are goal-directed, and hence only subject to external ethical considerations, the education of future professionals may not be. Professional education is typically about teaching students to acquire skills and habits of mind they will need in that profession. This is not a strictly goal-directed activity. It is about getting students to engage in particular kinds of performance (reflective, critical problem solving). There is good reason for this: we don't want the students to produce a "cure" or a "win" in a particular setting, rather we want them to have the right skills and habits for producing those outcomes in a variety of unanticipated settings. So this potential counter-example to the practice-oriented claim is less compelling than it first appears.

But even if education is partly about performative skills across most domains, there may be no generic performative skills involved. The requirements might vary quite dramatically from subject to subject. In some cases it may be about time management and the ability to work with certain constraints, ${ }^{12}$ and in others in might be about developing habits of mind that facilitate open-ended problem-solving. Global assessments of the propriety of enhancement within university education might thus still prove elusive.

There is something to this, but there is also one generic performative skill that I think is shared by a wide range of university subjects, and which can provide a ground for the generic regulation of student use of enhancement. The skill in question is that of "critical thinking". There is no official definition of what this consists in, but I will here adopt a definition proposed by Steven Brookfield. ${ }^{13}$ According to him, critical thinking is a skill made up of four processes: (1) identifying the assumptions that frame our thought and action; (2) checking the degree to which those assumptions are accurate and valid; (3) looking at our assumptions from different perspectives; and (4) on the basis of all this making informed decisions about what to believe and what to do. These four processes build upon a foundation of knowledge: students need to acquire certain facts and understand certain critical concepts and ideas before they can develop mastery of the four processes themselves. As will become apparent, this knowledge-based

\footnotetext{
${ }^{11}$ Note: I'm not arguing that they actually are. I'm simply imagining, for sake of argument, that someone might think this.

${ }^{12}$ Santoni de Sio et al (n 2) mention these possibilities.

${ }^{13}$ Brookfield, S. Teaching for Critical Thinking. San Francisco, CA: Jossey-Bass 2012.
} 
foundation is crucial to the argument I wish to make. But in any event, once the foundation is there, the four processes clearly constitute a set of performative skills. When we teach students to acquire the skill of critical, we want them to engage in the four different processes, and we assess them in an effort to determine whether or not they have engaged in those processes. We don't want them to bypass or shortcut the performance of these four processes. To do so would subvert the point of educational activity.

Why should one accept that critical thinking is a generic skill shared across most forms of university education? I have no decisive argument to offer, but it does appear to be a skill that is highly valued and emphasised across most forms of education. It is often claimed as the primary justification for continuing to teach arts and humanities; it is an essential process in scientific research and investigation; and it is critical in professional education too. Thus, for example, a good lawyer or doctor must be able to engage in a critical analysis of the patients and cases that come before them, questioning assumptions, interrogating and evaluating the evidence, and so on. So I think the first premise of my first argument is plausible: education is indeed a partly practice-oriented activity, and there is a generic performative skill that the activity is aimed at developing, namely the skill of critical thinking. The question now is whether the use of cognitive enhancing drugs would prevent students from engaging in that required performance.

\section{Does the use of cognitive enhancing drugs subvert the point of education?}

The focus now switches to premises (2) and (3) of the argument I sketched earlier on. These premises comes as a pair: premise (2) claims that a combination of deliberate practice and spaced repetition is crucial to developing the skill of critical thinking; premise (3) claims that use of currently-popular cognitive enhancing drugs undermines this combination of activities. The defence of both premises will not be decisive (few things in applied ethics are): the goal instead is to offer a plausible, empirically supported, connection between deliberate practice and spaced repetition and the skill of critical thinking, and a plausible, empirically supported, reason to think that use of cognitive enhancing drugs will tend to subvert both of these things. 
I start with the claim that deliberate practice and spaced repetition are central to critical thinking. At first, this may appear to collapse the previously-described skill of critical thinking into a very narrow space. Critical thinking has just been defined in terms of four distinct processes (identifying assumptions, checking assumptions, evaluating from different perspectives, and determining appropriate thought and action), which in turn are founded upon knowledge of important facts and concepts. I now seem to be claiming that this complex and multi-faceted skill can be reduced to two key elements. But this is not how premise (2) ought to be understood. My claim is not that critical thinking can simply be reduced to deliberate practice and spaced repetition; my claim is that both provide essential inputs into the development of critical thinking. I assume (hopefully plausibly) that the goal of education is to inculcate long-term changes in the performative skill of critical thinking and I argue that in order to do this students have to undertake educational tasks (preparing for exams, writing essays and assessments) through a kind of performance that involves deliberate practice and spaced repetition. Deliberate practice is widely-recognised as being essential to developing long-term mastery of skills; ${ }^{14}$ and it is also increasingly being recognised as essential to developing critical thinking skills. Critical thinking is difficult for many students. ${ }^{15}$ Several studies now suggest that the ideal interventions for cultivating this skill should focus on providing students with tools and techniques - such as argument-mapping software - that enable them to break the skill down into its component processes, and deliberately practice and master those components over multiple practice sessions.16 In addition to this, it is also widely recognised that spaced repetition is the best method for ingraining the detailed factual and conceptual knowledge that provides the foundation for critical thinking, and that spaced deliberate practice is best for inculcating long-term changes in memory and habit. ${ }^{17}$ At any rate, spaced repetition is better than alternative

\footnotetext{
${ }^{14}$ Ericsson, KA, Krampe, RT and Tesch-Romer, C. The Role of Deliberate Practice in Expert Performance. Psychological Review. 1993 100(3): 363-406; Ericsson, KA (ed) The Road to Excellence. Psychology Press 2014. ${ }^{15}$ Abrami, P.C., Bernard, R.M., Borokhovski, E., Wade, A., Surkes, M.A., Tamim, R. \& Zhang, D. (2008). Instructional interventions affecting critical thinking skills and dispositions: A stage 1 meta-analysis. Review of Educational Research, 2008, 78 (4): 1102-1134; Willingham, D.T.. Critical thinking: Why is it so hard to teach? American Educator. 2007, 3: 8-19

${ }^{16}$ Butchart, S., Bigelow, J., Oppy, G., Korb, K., \& Gold, I.. Improving critical thinking using web-based argument mapping exercises with automated feedback. Australasian Journal of Educational Technology. 2009, 25(2): 268-291; Abrami, P.C., Bernard, R.M., Borokhovski, E., Wade, A., Surkes, M.A., Tamim, R. \& Zhang, D. (2008); Instructional interventions affecting critical thinking skills and dispositions: A stage 1 meta-analysis. Review of Educational Research, 2008, 78 (4): 1102-1134; Dwyer, C., Hogan, M.J., Stewart, I.. An Evaluation of Argument Mapping as a Method of Enhancing Critical Thinking Performance in e-Learning Environments. Metacognition and Instruction. 2012, 7(3): 219-244. Some studies suggest that the skill can be improved in relatively short 8-12 week courses, but that this still requires deliberate and repeated practice, sometimes aided by the use of technologies like argument mapping software, not short cramming sessions

${ }^{17}$ Brown, P, Roediger, H.L, and McDaniel, M. Make it Stick: The Science of Successful Learning. Cambridge, MA: Belknap Press 2013; Susser, J and McCabe, J. From lab room to dorm room: metacognitive awareness and the use of spaced study. Instructional Science 2012 DOI 10.1007/s11251-012-9231-8; Carpenter, SK, Cepeda, NJ, Rohrer, D, Kang, SHK and Pashler, H. Using Spacing to Enhance Diverse Forms of Learning: Review of Recent Research and
} 
methods like cramming or binge-studying. This supports the view that the combination of deliberate practice and spaced repetition is central to developing the skill of critical thinking.

This brings us to premise (3) and the claim that the use of cognitive enhancing drugs undermines deliberate practice and spaced repetition. Initially, this looks like a tough sell. If cognitive enhancing drugs genuinely enhance certain cognitive attributes like concentration, memory, task-performance (etc) then surely it compromises neither deliberate practice nor spaced repetition? In fact, surely it facilitates both? Here is where we need to pay attention to the contemporary realities. My argument is not that enhancing drugs could never facilitate critical thinking. Rather, my argument is that the current limited empirical evidence in favour of an enhancing effect, combined with common patterns of usage among students, make it likely that both deliberate practice and spaced repetition are being undermined. Furthermore, I argue that even if the drugs have a genuine enhancing effect, they are likely to be used in a way that does not facilitate deliberate practice and spaced repetition. So in either case, premise (3) is justified and we can tailor a regulatory intervention to combat the problems.

To defend this view, we need to start by reviewing the available evidence on the cognitive enhancing effect of the most commonly-discussed drugs (methylphenidate, dextroamphetamines and modafinil). In recent years there have been several systematic reviews and metanalyses that help us to assess their effectiveness. ${ }^{18}$ As the authors of these studies note, since trials on healthy adults are not pre-registered, we have no way of knowing the extent of publication bias. This should make us somewhat wary of the available evidence. ${ }^{19}$ Nevertheless, taking that onboard, several key trends seem to emerge. First, there is some evidence that stimulants like methylphenidate and dextroamphetamines may genuinely improve memory and memory consolidation. ${ }^{20}$ Second, positive findings in relation to other cognitive functions for the stimulants are

\footnotetext{
Implications for Instruction. Educational Psychology Review, 24: 369-378; an excellent source for empirical studies of spaced repetition is Gwern, Spaced Repetition: Literature Review - Updated September 2015 http://www.gwern.net/Spaced\%20repetition

${ }^{18}$ Repantis D, Schlattmann P, Laisney O, Heuser I. Modafinil and methylphenidate for neuroenhancement in healthy individuals: a systematic review. Pharmacological Research 2010, 62:187-206; Hall WD, Lucke JC. Enhancement uses of neuropharmaceuticals: more caution and skepticism needed. Addiction 2010, 105:2041-2043; Smith, E and Farah, M. Are Prescription stimulants smart pills? The Epidemiology and Cognitive Neuroscience of Prescription Stimulant Use by Normal Healthy Individuals. Psychological Bulletin 2011, 137(5): 717-741; Farah, M, Smith, E., Ilieva, I. and Hamilton, R. Cognitive Enhancement. WIREs Cognitive Science, 2013, 5(1): 95-103; and Bagot, K S and Kaminer, Y. Efficacy of stimulants for cognitive enhancement in non-attention deficit hyperactivity disorder youth: a systematic review. Addiction 2014, 109(4): 547-557

${ }^{19}$ Smith and Farah (n 18) and Farah et al (n 18).

${ }^{20}$ Smith and Farah (n 18); Farah et al (n 18); and Bagot and Kaminer (n 18)
} 
far more mixed, with some positive results, some null results, and some occasional findings of impairment. ${ }^{21}$ Third, the clearest positive finding in relation to modafinil has to do with attention and wakefulness in non-sleep-deprived adults; and wakefulness, executive function and memory in sleep-deprived adults. ${ }^{22}$ This is not surprising given the on-label indications for this drug. Fourth, the positive effects of modafinil on attention and executive function tend not to sustain over repeated dosages, and users of the drug may build up a sleep-deficit from use of this drug that needs to be repaid at a later time. ${ }^{23}$ Fifth, and finally, there seems to be evidence for an overconfidence effect in relation to each of the drugs: even if the actual performance enhancement is negligible, experimental subjects tend to think they have improved greatly. ${ }^{24}$ All this evidence seems to support the claim that the enhancing effect is likely to be minimal (even if there are a few genuine benefits), and users may be biased into selfundermining patterns of behaviour based on mistaken belief in the enhancing effect.

This is particularly interesting in light of Vrecko's recent phenomenological study on patterns of student usage of enhancing drugs. In a series of interviews at elite US universities, Vrecko found that students tended to use these drugs to help them complete academic coursework in sustained bursts of activity. They did so because the drugs helped to remove the psychological barriers to starting academic work and allowed students to feel better about the work whilst they were doing it. ${ }^{25}$ This suggests that the emotional benefits of these drugs may often be greater than the cognitive ones.

So does this mean that the use of these drugs subverts critical thinking? The picture is nuanced. None of this evidence, positive or negative, suggests that the use of cognitive enhancing drugs directly benefit the cultivation of critical thinking. The drugs do not allow a student to bypass or skip any of the four stages of critical thinking (unlike, say, plagiarism or purchasing an essay). Students still need to identify their assumptions and evaluate them from a range of perspectives. Furthermore, there are still some tensions between usage and critical thinking. It seems likely — and this appears to be confirmed by studies such as Vrecko's - that these drugs, even if they have a genuine enhancing effect in the short term, are primarily being used to help students to complete academic work in short bursts of time and effort. Thus, when they have an

\footnotetext{
${ }^{21}$ Smith and Farah (n 18)

${ }^{22}$ Repantis et al (n 18); and Farah et al (n 18).

${ }^{23}$ Repantis et al (n 18); and Farah et al (n 18).

${ }^{24}$ Repantis et al (n 18); Smith and Farah (n 18); and Farah et al (n 18).

${ }^{25}$ Vrecko, S. Just how "cognitive" is cognitive enhancement. AJOB Neuroscience 2013 4(1): 4-12
} 
assignment due or an exam pending, students take the drugs to fuel cramming or binge writing sessions. The drugs, consequently, function as psychological crutches and procrastination aids. Students can put off doing work for long periods of time because they know (or feel overconfident) that the drugs will help them get it done quickly when the pressure mounts. If this is the common pattern of usage, then it would indeed appear to undermine critical thinking, irrespective of any short term enhancing effect. As mentioned, critical thinking takes time and effort. Cramming and bingeing are probably the worst ways to inculcate this skill. By facilitating this sort of learning strategy, the current crop of cognitive enhancing drugs are likely to be undermining critical thinking.

If this is right, then my first argument is successful: there is reason to think that current patterns of use of cognitive enhancing drugs subvert the point of education and this (for reasons to be discussed more fully below) may warrant regulatory intervention on the part of universities. But there are two criticisms that may block this inference. ${ }^{26}$ The first is that the preceding argument assumes a false dichotomy: it assumes that if the drugs facilitate short, cramming sessions they will undermine deliberate practice and spaced repetition. But this need not be the case: the drugs could be used to fuel many practice sessions over a spaced period of time. The other criticism is that this argument neglects to consider the relevant counterfactual cases. In other words, it seems to assume that students who use these drugs as procrastination aids would not be procrastinating anyway and would be better able to attain the right kind of performance without their use. But this is not at all clear: such students may do much worse without these drugs.

Both of these criticisms have credibility. But several points should be borne in mind. The first criticism runs contrary to what appears to be the current norm of practice among students. Furthermore, as will become clear below, even if the drugs could be used to good effect by some students, regulatory intervention may nevertheless be warranted. It seems pretty clear that, even if there is some enhancing effect from these drugs, the drugs themselves are not directly facilitating the desired educational performance; they only facilitate this performance when used in the right way. Consequently, regulatory intervention may be appropriate because it encourages the right kind of usage. This is true even for the student who seems be counterfactually

\footnotetext{
${ }^{26}$ I would like to thank an anonymous reviewer for drawing these objections to my attention.
} 
benefitting from current patterns of usage. They could be doing even better if the right kind of regulatory mechanism exists to facilitate a superior performance. This is something I will suggest below.

\section{So how should universities regulate student usage?}

If the first argument is accepted, we can turn to the second. Where the first argument identified particular mechanisms by which use of cognitive enhancing drugs might subvert education-viz. by functioning as procrastination aids that encourage students to bypass the deliberate practice and spaced repetition that are central to critical thinking - the second argument develops a regulatory intervention that targets those mechanisms. It claims that one appropriate way in which universities could regulate student use of these drugs would be through a system of voluntary commitment contracts. This regulatory intervention would help target the mechanisms of subversion, without being too overweening, coercive or otherwise inappropriate for an educational institution.

A "commitment contract" is a device that can be used to overcome procrastination and weakness of the will. ${ }^{27}$ A person commits to achieving a goal or performing a practice and signs a contract with another party that requires them to pay out a penalty if they fail to achieve their goal or perform their stated practice. A typical example might be a commitment to lose weight which, if not achieved, results in a payment to one's least favourite political cause. There are a number of commercial websites and apps that allow one to create and enforce commitment contracts. ${ }^{28}$ And available evidence suggests that commitment contracts are effective tools for overcoming procrastination and inculcating good habits. ${ }^{29}$

If this is right, and if as previously argued currently popular crop of cognitive enhancing drugs function as procrastination aids, then I submit that a commitment contract system is the ideal way in which to regulate student usage: it is a system of

\footnotetext{
${ }^{27}$ Ayres, I. Carrots and Sticks: Unlocking the power of incentives to get things done. New York: Bantam 2010

${ }^{28}$ For example, the SticKK method, created by Yale Economists Dean Karlan and Ian Ayres (http://www.stickk.com). Also, Beeminder, which tries to enforce commitments on a more regular basis (e.g. a $\$ 10$ penalty for failing to do something relevant to one's goal every day): http://www.beeminder.com

${ }^{29}$ Gine, X., Karlan, D., and Zinman, J. Put your money where your butt is: A commitment contract for smoking cessation. American Economic Journal: Applied Economics. 2010, 2(4): 213-235; Royer, H., Stehr, M. and Sydnor, J. Incentives, Commitments and Habit Formation in Exercise: Evidence from a Field Experiment with Workers at a Fortune-500 Company. American Economic Journal: Applied Economics, Forthcoming.
} 
regulation that directly targets the education-specific concern that arises from the use of enhancing drugs to fuel cramming sessions.

How would this system of regulation work in practice? Let's assume that the goal is to completely prevent students from using these drugs (we will consider an alternative, less restrictive, goal in a moment). The idea then would be to get students to voluntarily sign a commitment contract in which they commit to not using these drugs. If they are found to be using the drugs (either through drug testing or other indirect evidence), they will incur some penalty. The penalties could, in principle, be anything, but given that the concern here is with the educational mission of the university, and the potential impact of such drug usage on educational performance, a penalty that directly impacts on that performance would seem most appropriate. I would suggest some reduction or capping of marks, which would fit with common penalties for late submission of assignments or academic misconduct. That is the basic idea. Now, let's consider potential objections.

First, let's address the form that such a regulatory intervention should really take. In the initial sketch, I assumed that we want to prevent student usage of these drugs. This seems appropriate given the currently mixed state of the evidence on these drugs and their potentially harmful side effects. (In this respect, the general ethical concern with harm reinforces my proposed model of regulation, without providing an alternative basis for it. This becomes important when dealing with the worry about the paternalistic features of my proposal, which I discuss below.) But what should we do if think there is a genuine enhancing effect? I argue that this should not radically alter the regulatory approach. In that case, there is still the problem that students would use these short-term enhancing effects to fuel cramming sessions, and this would still subvert the point of the activity. The only change that needs to be made in this scenario is that, instead of committing to not use the drugs, students commit to using them in a particular way (e.g. to fuel several enhanced study sessions over spaced intervals). In this way, students could be encouraged to use the drugs in the most responsible and beneficial manner. This could again be enforced through a system of testing, only this time the tests would need to be more regular to ensure that students are keeping up spaced regular usage. Admittedly, this may seem like an odd thing for universities to do, but if we are convinced of the enhancing effects, and we wish to encourage effective usage, the oddness soon dissipates. 
A second objection might point to the potentially draconian methods of enforcement. Surely we don't want to have students routinely drug tested or subjected to drug raids to make sure they are not using these substances (or are using them in the right way)? Surely that would create an unhealthy relationship of suspicion and mistrust between educators and students? Maybe, but it is worth noting that drug tests on student athletes are already common. Similarly, there are other regulatory interventions that create a relationship of mistrust between educators and students that seem unobjectionable. For example, the use of plagiarism detection software is sometimes claimed to create such an atmosphere and yet most people agree that it is an appropriate regulatory intervention given the risks that plagiarism poses to desired educational performance. More importantly, the model I propose is strictly voluntary. Students are not forced to sign up to these contracts. The intention is to empower students so that they do not fall into bad habits associated with such drug usage. This empowerment ethos should lessen the risk of creating an unhealthy climate of suspicion and is arguably less draconian than many other forms of regulation that are imposed on students. Some might dispute this by arguing that within the hierarchical and competitive atmosphere of the typical university, the voluntariness of this system would soon evaporate. Students would come under enormous pressure to signal that they are engaging in the right kind of performance by signing up to the contracts. In this manner, the system would become threatening or coercive, amounting to little more than the offer to 'sign up or else?' This is an attractive criticism but it seems wrongfooted. We need to consider what it means to present someone with a coercive offer. Take the accounts of coercion defended by the likes of Wertheimer or Nozick, which are popular in the literature. ${ }^{30}$ These accounts define coercion as the attempt to make someone worse off relative to some existing baseline if they do not take up an offer. Nothing in my proposal exhibits these features. Students are only being made worse if they take up the offer and if they fail to comply with its terms. If they absent themselves from the system, they are not being made worse off than they would otherwise have been. Things will be as they are and, for instance, nothing in their transcripts will reflect the fact that they didn't use the system. In effect, they impose the risks on themselves. In any event, if one is still concerned that the signaling pressure brought to bear on students will be immense, one could institute additional regulatory measures that mitigate against this.

\footnotetext{
${ }^{30}$ Nozick, R. Coercion. In Sidney Morgenbesser, Patrick Suppes and Mary T White (eds), Philosophy, Science, and Method: Essays in Honor of Ernest Nagel (St Martin's Press, 1969) 440; Wertheimer, A. Coercion (Princeton University Press, 1987)
} 
For example, one could stipulate that information pertaining to the contracts will not be released or confirmed to (say) potential future employers. This could mitigate any risk of excess pressure and retain the empowering aspects of the proposal. ${ }^{31}$

Third, let's consider the possibility that the model proves too much. If it is appropriate to regulate student use of these drugs because they function as procrastination aids, then isn't it appropriate to regulate everything else that works in the same way? Facebook, friends, parties, social clubs and many other phenomena function as procrastination aids. Would it not be terribly paternalistic to introduce an analogous contract system to encourage students to avoid or limit their exposure to those things? And does this not imply that my proposal too is terribly paternalistic? There are a few responses to this. For starters, if the regulation of these other behaviours was done in a strictly voluntary fashion it might not be that objectionable. Indeed, this is something we might like to seriously consider. But even still, there are important disanalogies between the different types of procrastination aid. One of these is that the use of cognitive enhancers is directly linked to the educational mission of the university: excepting those with valid prescriptions, students use enhancing drugs, and are encouraged to use them by friends, in order to improve their performance on the very thing universities are trying to improve through traditional educational methods. In this respect, the purported use falls squarely within the regulatory purview of the university. It is not a strictly private affair. The drugs are used by students in their role as students, and it is in that role that universities care about them. This intimate link between the intended effect of the drugs and the university's mission makes the university's focus on the regulation of such drug-use less obviously inappropriate and paternalistic. It is also what helps to plug the gap between premise (4) and (5) of the first argument that I defended above, by explaining why regulatory intervention might be justified. Spending time with friends, going to parties and browsing through one's Facebook feed are, at best, peripheral to the educational mission. They are part of the private and extra-curricular lives of students. ${ }^{32}$ Universities should be less concerned

\footnotetext{
${ }^{31}$ Relatedly, an anonymous reviewer worries how universities would deal with students who have valid prescriptions for these drugs. I think the simple answer is that universities wouldn't have to deal with such students under this regulatory proposal. Students being prescribed drugs like, say, methylphenidates or modafinil presumably have valid grounds for this: they need the drugs in order to be brought onto an equal footing with their peers. There is no reason to penalise them. Furthermore, such students are unlikely to volunteer for the system so this is unlikely to be a practical problem.

${ }^{32}$ Admittedly, contribution to social clubs and engagement with other extracurricular is increasingly expected of students. There is also increasing regulation of student's private lives, particularly through the monitoring of social media usage. There is a debate to be had about whether this is appropriate. That debate does not, however, affect the arguments I am making in relation to the use of enhancement drugs.
} 
with students in those private and extra-curricular roles. There is consequently less justification for trying to intervene and regulate those behaviours.

This also explains why regulating usage of the drugs solely on the grounds of their harmfulness would be inappropriate from the university's perspective. Again, there are many activities that students undertake that could be harmful. But most of these would not fall within the direct regulatory purview of the university because students would not be engaging in them qua students. It is the fact that the usage of enhancement drugs is tied to educational performance, and may also have a harmful effect, that makes regulation highly appropriate. That said, the proposal is undoubtedly somewhat paternalistic. But here, again, I think the voluntariness of the system blunts some of the complaints one could have about that paternalism.

This leads to another complaint. Why are universities the appropriate regulators of this type of drug usage? Why not regulate at the point of sale or prescription? The answer to this again highlights the domain-specific nature of the argument I am making. Recall, I am not offering a general ethical objection to the use of enhancement drugs. I am offering an objection that is specifically tailored to the nature of education and the possible subversion of education through the use of these drugs. This is why the university, as an educational institution, is the appropriate regulator of this type of usage. It is possible that outside of that domain there are also reasons to encourage the use of enhancement drugs. Others have made such arguments. ${ }^{33}$ It is also possible that there are reasons to discourage the use of enhancement drugs outside of the educational domain. There could be other regulatory interventions designed to address those external issues. This doesn't alter the appropriateness of my proposed system of regulation within the domain of education. There is nothing unusual about this suggestion. For example, many universities regulate student sexual assault or harassment in parallel to the general civil/criminal regulation of sexual assault and harassment. The systems work in parallel, and there are can be different definitions and sanctions tailored to the needs of the different domains. If this kind of parallel regulation is appropriate in the case of sexual assault and harassment, there is no reason to think it wouldn't be appropriate in the case of student use of enhancement drugs.

\footnotetext{
${ }^{33}$ Santoni et al (n 2).
} 
Finally, and perhaps most importantly, let's consider the fact that a voluntary system might be ineffective. After all, who would sign up for it? Would students really commit to drug testing or equivalent invasions of privacy? This is certainly a potential weakness of the system, but such weakness seems like the price one needs to pay in order to avoid a more objectionably paternalistic and coercive system. Nevertheless, the weakness could be combatted with an effective educational campaign. When students arrive at university, they could be informed of the problems (or potential benefits) of using cognitive enhancing drugs and the advantages of the commitment contract system. If necessary, certain sweeteners or incentives could be added to the programme. For example, students who successfully complete a semester or year on the system could receive some academic prize or commendation. In this way, reluctance to participate could be overcome. This would have to be carefully calibrated in order to minimise potential coercive impact of such sweeteners, so there is balancing act to be undertaken, but this could work if the signaling value of the prizes is minimal.

Furthermore, in relation to possible ineffectiveness, the proposal being mooted here should really be viewed as a proposal for a regulatory experiment, not a proposal for blanket regulatory reform. This is why I have not said anywhere in this article that universities ought to introduce regulations concerning student use of enhancement drugs. I have merely argued that there may be grounds for doing so and, if so, that an appropriate regulatory intervention might involve voluntary commitment contracts. Any university thinking about introducing such a policy should be prepared to gather data about effectiveness and reassess at a later point. This may be difficult given that data about general prevalence of these drugs are hard to come by. But regulatory experiments such as the one I am suggesting, by some universities, could actually be a boon in this respect. Comparison of such an experimental regime with other, more traditional regimes could help us in making inferences about the effect of these drugs. That's not a good reason to introduce the policy in the first place, but it may be a beneficial side effect. It would also help to assess the strengths and weaknesses of this regulatory proposal, particularly whether it leads to excessive pressure and whether universities can act as effective regulators in this regard. 


\section{Conclusion}

In summary, when thinking about how (or whether) we ought to regulate student usage of cognitive enhancing drugs, it is helpful to adopt Santoni de Sio et al's evaluative framework and ask what is the nature of education in the first place. Adopting that framework, I have made two arguments. First, I have argued that education is a partly practice-oriented activity, directed primarily at cultivating the skill of critical thinking and that the current crop of cognitive enhancing drugs (methylphenidate, dextroamphetamines and modafinil) may subvert or undermine that activity by functioning as procrastination aids. What is more, I have argued that this is true even if these drugs have some genuine enhancing effect. Second, in light of this, I have argued that an appropriate system of regulation would be a voluntary commitment contract system. Such a system would empower students to take control of their own learning experience, and avoid the pitfalls of misusing cognitive enhancing drugs. This proposal is modest. It is not mooted as something that all universities must do; it is merely mooted as something that could be justified and could contribute to a system of regulatory experiments that allows us to glean more information about the impact of these drugs on the educational process.

Acknowledgements: The author would like to thank two anonymous reviewers for feedback on a previous draft of this paper. 